\title{
Alternative Design Method To Improve Accommodation Room On Merchant Ship Accounting For Crew Condition During International Voyages
}

\author{
Aditya Rio Prabowo ${ }^{1}$, Bangun IR Harsritanto ${ }^{2}$, Jung Min Sohn ${ }^{3}$, Joung Hyung Cho ${ }^{4}$ \\ \{aditya.rixx@gmail.com ${ }^{1}$, bangunirh@arsitektur.undip.ac.id ${ }^{2}$, jminz@ pknu.ac.kr³ ${ }^{3}$ \} \\ Universitas Sebelas Maret, Jl. Ir. Sutami No.36A, Surakarta 57126, Central Java, Indonesia ${ }^{1}$ \\ Pukyong National University, Nam-gu, Yongso-ro 45, Busan 48513, South Korea ${ }^{134}$ \\ Universitas Diponegoro, Jl. Prof. Soedharto S.H., Semarang 50275, Central Java, Indonesia ${ }^{2}$
}

\begin{abstract}
This work aims to assess possibility to set-up relaxation space on mostfrequent used by seafarer for resting and relaxing. The focus is addressed on the sleeping accommodation and mess room, with three approaches to set-up such space are considered by reviewing coloring, lighting and flooring. To conduct the assessment, fundamental literature of fatigue phenomenon is presented based on pioneer works in shipping activity. After solid background and necessity are clarified, the design requirement of merchant ship for crew accommodation is reviewed to ensure the design planning for relaxation space is also satisfy classification standard. Several forms of relaxation space's concept based on different approaches are presented in discussion. Finally, from three approaches, it is concluded that coloring is the suitable in setting-up a relaxation room, especially in sleeping accommodation. Further design on the mess room requires collaboration of three approaches to reach good comfortableness level.
\end{abstract}

Keywords: relaxation space, merchant ship, arrangement regulation, design approaches, improved layout scheme.

\section{Introduction}

International trading has become vital activity for various countries across the globe to fulfil daily necessities, including raw material and advance industrial product. In this case, shipping parties hold essential role to conduct such activity as they act as transporter of trading cargo of clients on different locations. Operational of ship during voyage will directly affect condition and quality of the cargo, as delay in distribution may cause expiration and costly loss. Such situation is prioritized to be avoided which several efforts are addressed to overcome this challenge, e.g. crew training and adequate education for seafarer. However, these methods are not always to be the best solution as different sea condition can be faced and inflict stress, anxiety of the ship crew. Even though well preparation and training have been performed to organize involved personnel in a voyage, occurrence of the mentioned symptoms is still possible to exist, and causes remarkable accident on sea. Assessing this situation, there is a demand to provide more flexible solution to ease or even cure the negative symptoms during a voyage which can also be used as recreation facility to optimize provided space in crew accommodation of merchant ship.

ICCSET 2018, October 25-26, Kudus, Indonesia

Copyright (C) 2018 EAI

DOI 10.4108/eai.24-10-2018.2280614 
This work is started to review encountered challenges by the seafarer, and their consequences during ship operation is conducted to complete trading mission. Observation is focused on the negative indication which occurs on ship crew as result of their activity. In the next stage, several space design perspectives are assessed to propose alternative solution by optimizing crew accommodation space as convalescence facility.

\section{Personnel condition of merchant ship in international voyage}

Observation on the maritime-based accidental phenomena indicates that approximately $80 \%$ of the accidents occur due to human error. This statement is also stated by Donaldson [1] that points human error as the root of all accidents. Assessment on accident on maritime territory has been conducted for relative long time, and fatigue is categorized as either main cause or a major contributor. Tragic disasters across the globe have been concluded as a product of such symptom on seafarer, e.g. collision of the Herald of Free Enterprise which caused massive human-life loss, and grounding case of the Exxon Valdez in Alaska which spilled remarkable volume of crude oil. Survey on a numbers of mariners from was conducted by Sanquist et al. [2] which points out fatigue problem in shipping industry due to their sleeping characteristics, such as previously listed in report of Reyner and Baulk [3]:

a) Overall reduction in sleep time. i.e. working at sea (6.6 hours) and at home (7.9 hours)

b) Fragmented (and therefore poorer quality) sleep

c) Having to attempt to sleep at physiologically inappropriate times

d) Insufficient breaks for rest and poor sleep quality in the main sleep period

e) Long work days

f) Watch keepers slept less and their sleep was of poorer quality than that of day workers

Various efforts are taken as proposed solution of the fatigue by the industry, which one of them is regulation of working hour limits and rest-relax periods. In the provisions of International Labor Organization (ILO) 180, working limit is determined to be 14 hours in a day (24-hour period) or a minimum rest period 10 hours in any 24-hour period.

\section{Design requirement for frequent-used crew accommodation}

Ship arrangement is designed for long-term operation with assumption almost-no transit on port in certain condition. Therefore, various accommodations for the crew are created to provide daily necessities. Two of the most frequent-used accommodations are sleeping cabin and mess room. Sleeping cabin is private room for seafarer to take a rest in the end of their shift. On other hand, the mess room is used as social facility to interact with other crew during their mid-day rest period. Requirement related to these accommodations is presented in this work according to Design and Construction of Crew Accommodation provided by Bureau Veritas, France [4]. 


\subsection{Sleeping accommodation}

In ships other than passenger ships, an individual sleeping room shall be provided for each seafarer. Separate sleeping rooms shall be provided for men and for women. A separate berth for each seafarer shall in all circumstances be provided. The minimum inside dimensions of a berth shall be at least $198 \mathrm{~cm}$ by $80 \mathrm{~cm}$. In single berth seafarers' sleeping rooms the floor area shall not be less than:

a) 4.5 square $m$ in ships of less than 3,000 gross tonnage,

b) 5.5 square $\mathrm{m}$ in ships of 3,000 gross tonnage or over but less than 10,000 gross tonnage,

c) 7 square $\mathrm{m}$ in ships of 10,000 gross tonnage or over.

\subsection{Sleeping accommodation}

Mess rooms shall be located apart from the sleeping rooms and as close as practicable to the galley. Mess room facilities are normally separate. They may be taking account of ship owners' representatives' information such as the size of the ship and the distinctive cultural, religious and social needs of the seafarers. Details of arrangements shall be as follows:

a) On ships other than passenger ships, the floor area of mess rooms for seafarers should be not less than 1,5 square m per person of the planned seating capacity.

b) In all ships, mess rooms should be equipped with tables and appropriate seats $(34 \mathrm{~cm}$ minimum breadth), fixed or movable, sufficient to accommodate the specified number of seafarers likely to use them at any one time.

c) There should be available at all times when seafarers are on board, such as a refrigerator, which should be conveniently situated and of sufficient capacity for the number of persons using the mess room or mess rooms; facilities for hot beverages and cool water facilities.

\section{Review on alternative improvement method for existing design}

\subsection{Color ambiance}

There is no strict regulation related coloring for accommodation rooms in ship. According to International Labour Organization [5], the interior walls and ceilings of all parts of the crew accommodation shall be painted or covered with a suitable material. Paint shall be white or light in color. Therefore, designing alternative relaxation room with color approach is possible to be conducted. The purpose of the relaxation room is providing sustainable facility for seafarer during both short and long-term voyage. In this case, concept of mood improvement is proposed to be implemented in this research. This concept is carried out through color implementation. As included in research by Kurt and Osueke [6] related to effect of color on the moods, previously Wright [7] indicate that there are four psychological primary colors: red, blue, yellow, and green. They relate, respectively, to the body, the mind, the emotions, and the essential balance between these three. The emotional effects of the basic colors are as follows: 
a) Red. This color has the longest wavelength, which indicates several characteristics, such as powerful, strong, and very basic color.

b) Yellow. According to pioneer works of Eiseman [8], this color is essence of joyful, outgoing, open, and friendly. In the psychological aspect, yellow is the strongest color.

c) Green. This color is considered as medium to calm nerves. It gives a sense of refreshment, harmony, and equilibrium.

d) Blue. This color encourages intellectual activity and logical thought. In the same evidence about raising blood pressure with red, blue is applied to lower the blood pressure, especially in medical and engineering.

Based on several literatures, it is found that green is the major color which deliver relaxation feels to the resident or people who visit a room with this color type. Sample of relaxation room with green-color implementation presented by Best Design Idea [9] is shown in Figure 1.

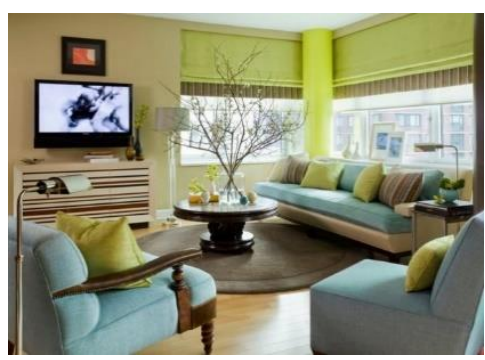

(a)

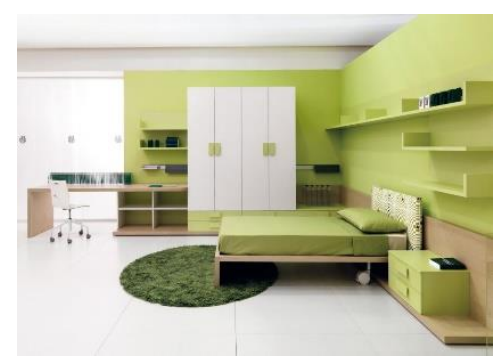

(b)

Fig. 1. Reference for green color implementation to develop relaxation facilities in merchant ship: (a) mess room, and (b) sleeping accommodation (Illustration can be accessed in Best Design Idea [9])

\subsection{Lighting configuration}

Role of lighting in providing relaxation for crew can be included as a vital criterion. Technology in this term has been massively developed, with conclusion in form of Light Emitting Diodes (LEDs). This invention is used by Johnson and Toffanin [10] in the University of Groningen to makes relaxation instrument entitled the Light Shower which consists of a chair which can be raised into a cylinder with a diameter of about $1.5 \mathrm{~m}$. Illumination is provided by RGB LEDs placed above and below the dome to create a uniform field of light. The brightness of the light depends on the color and intensity chosen by the observer, with a maximum of 500 lux. Similar concept is proposed to be designed on merchant ship with more casual and comprehensive styles. A lighting company, Philips with several parties are designing simple design for relaxation space by putting relax chair and combination of dark and light illuminations with performance of yoga (see Figure 2). This performance type can be solution besides brain-based games such as chess, and active sport, e.g. basketball and table tennis. 


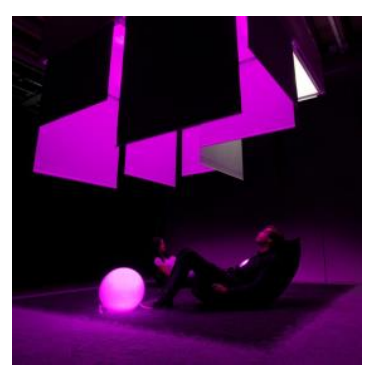

(a)

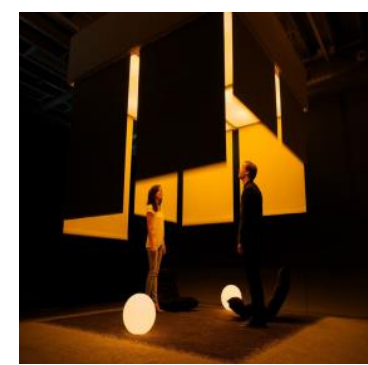

(b)

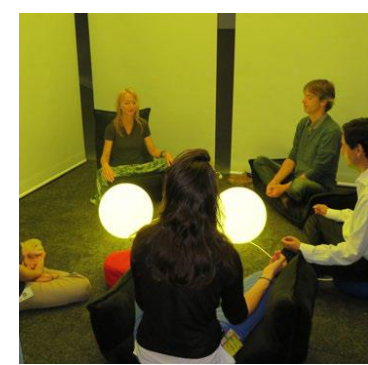

(c)

Fig. 2. Concept of relaxation space using lighting technique: (a) dark illumination, (b) light-color illumination and (c) combination with yoga (Illustration refers to [11]).

\subsection{Flooring design}

Application of flooring design can help the relaxation room to be more comfortable as it will reduce noise induced by ship engine and pump. Additionally, it will provide more aesthetic value and elegant atmosphere when crews takes a rest to recover their energy, or just performing yoga in this room. Therefore, mood should be well created during their stay and relaxation period. Combination with color scheme according to Oxbridge [12], there are three approaches:

1. Tonal - use just one color but varying tones of it throughout a room or use more than one color but all with the same depth of tone.

2. Harmonious - pick colors next to each other or near each other on the wheel. These schemes generally give a look that's easy to live with and are tranquil and restful.

3. Complementary - or 'contrasting' colors lie opposite each other on the color wheel. Complementary colors generally inject some life into a scheme, are more daring and will make more of an impact but might not be so easy to live with.

Several steps are recommended to make room to be more effective with collaboration of coloring and flooring, especially for arrangement design in merchant ship. To make a room appear larger: choose colors from the cool end of the color wheel, paint all surfaces the same color, keep flooring dark and walls light, the floor space will appear to expand. To make a room appear cozier: choose colors from the warm side of the color wheel, a sunny yellow will 'heat up' a room, but don't go overboard, complement it with a white ceiling and woodwork to keep it looking fresh, when using bright colors such as orange and red, remember to maintain balance by keeping the floor and carpet neutral. Flooring option based on carpet color and application of carpet in several spaces based on Oxbridge [12] is shown in Figure 3. 


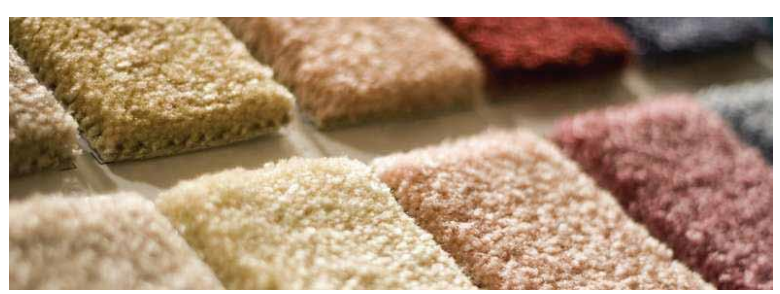

(a)

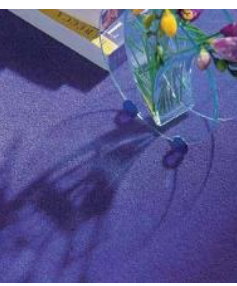

(b)

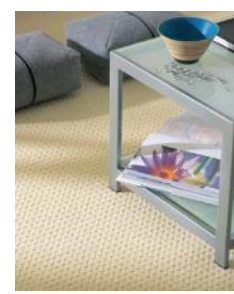

(c)

Fig. 3. Flooring design for relaxation room: (a) alternative carpet color, (b) application dark color on floor and (b) stability sense provided by light-brown color on carpet (Referring to floor design in [12]).

\section{Preliminary layout scheme for relaxation spaces}

Discussion of both standard regulation for crew accommodation and existing room design has been successfully conducted in previous sections. As an output, a set of preliminary layout design for relaxation space is presented in Figures 4 and 5 for sleeping accommodation and mess room. Fundamental consideration for the sleeping space is room dimension should fulfill at least 7 square $\mathrm{m}$. The designed room is addressed for two seafarer with personal activity to pursue their hobbies, such watching movie, reading book and playing game is also possibly performed in this space. Report and job-related activity are included in the design with table and chair provisions are provided.

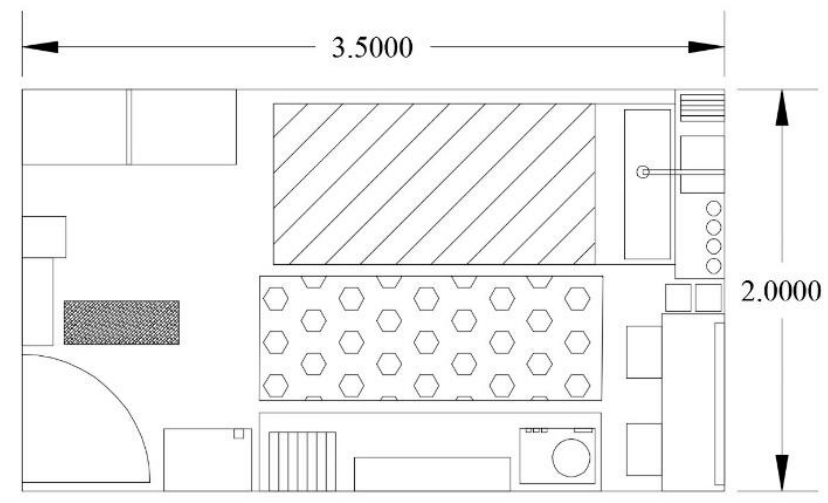

Fig. 4. Preliminary design for the sleeping accommodation. Presented values are in meter. 


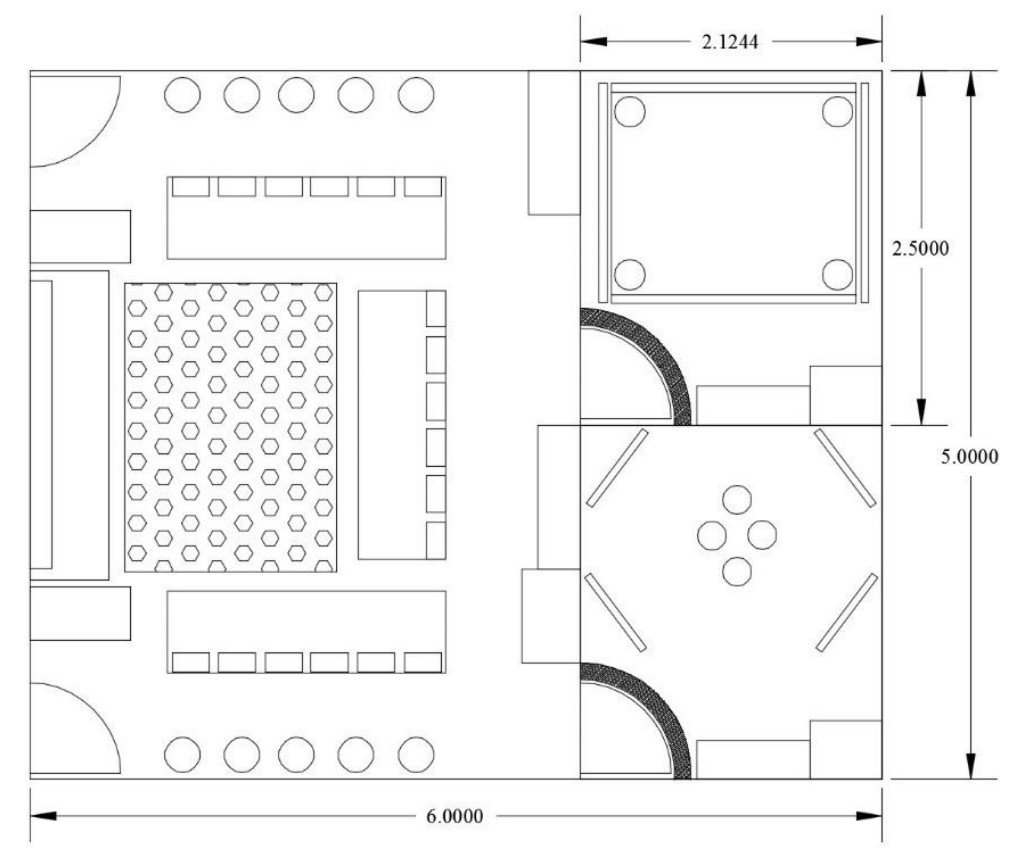

Fig. 5. Design for the mess room including relaxation spaces for seafarer. The unit is meter.

As for the mess room, concept of large movie hall is adopted which the designed capacity is approximately $25 \sim 30$ persons. This number is considered based on typical seafarer/crew in merchant ship. Behind the hall, a pair of silent relaxation spaces is designed. One space aims to provide relaxation through illumination or lighting concept with additional relaxing chair can be considered in depends on situation. However, this room still can be optimally used without the chair as wool carpet for flooring has been installed. Similar concept is applied on the second relaxation space which is addressed for yoga and reading. In order to keep sanitary of this room, visitors have to put their shoes or slipper in shoe rack. Application of flooring carpet is also used on the wall and ceiling to make sound proof and give relaxing atmosphere.

\section{Conclusions}

Assessment of room arrangement and labor regulation related to crew accommodation in merchant ship indicated high possibility for future development. Proposal for relaxation space as sustainable facility for crew in either short or long term voyage, is considered by applying color, lighting and flooring schemes on sleeping provision and mess room. Application of natural color, such as light green is found more suitable for relaxing atmosphere. Application of color approach is mainly focused on furniture and bed color which can be fitted with wall paint requirement. In terms of the lighting option, design of room should be conducted more detail as it will providing a relative new relaxation space by using mess room. Combination 
with flooring will be highly recommended considering the space will have multiple utility, such as take-rest facility, passive sport - yoga and reading room similar to combination of living room and library. Based on the mentioned schemes, color approach is the most suitable for fast regeneration of accommodation room in order to provide higher level of relaxation. However, for long term effect, and considering voyage from Asia through Europe through Malacca Strait, which causes monthly journey, design of relaxation space by collaborating three schemes is highly recommended. The next stage of this study will be focused on landscape design and interior model for the relaxation room accounting for natural and art sense of naval designer.

\section{References}

[1] Donaldson, “Safer Ships, Cleaner Seas. Report of Lord Donaldson's Enquiry into the Prevention of Pollution from Merchant Shipping," 1994.

[2] T. F. Sanquist, M. Raby, A. Forsythe, and A. B. Carvalhais, "Work Hours, sleep patterns and fatigue among merchant marine personnel," J. Sleep Res., pp. 245-251, 1997.

[3] L. Reyner and S. Baulk, "Fatigue in ferry crews: a pilot study," Seafar. Int. Res. Cent., 1998.

[4] Bereau Veritas, Bureau Veritas: Accommodation Design and Construction of Crew Accommodation in respect of Title 3 of Maritime Labour Convention 2006. France: Marine Division, Bureau Veritas, 2012.

[5] The Secretary of State for Transport Switzerland, International Labour Organization: Merchant Shipping 1997 No. 1508. The Secretary of State for Transport Switzerland, 1997.

[6] S. Kurt and K. K. Osueke, "The effects of color on the moods of college students," SAGE Open, pp. 1-12, 2014.

[7] A. Wright, "How it works," 2008. [Online]. Available: http://www.colouraffects.co.uk/how-it-works.

[8] L. Eiseman, Color: Messages and meanings-A Pantone color resource. US: Hand Books Press, US, 2006.

[9] bestdesignideas.com, "Best Design Idea: Combination of the green color in the interior," 2016. [Online]. Available: http://bestdesignideas.com/combination- green-colorinterior.

[10] A. Johnson and P. Toffanin, "Self-chosen Colored Light Induces Relaxation," 2012.

[11] Philips, Philips: Adaptive relaxation space. the Netherlands: Philips Design \& Innovation Communications, 2013.

[12] Oxbridge, Oxbridge: Interior design guide. UK: Oxbridge Flooring, 2011. 